\title{
Technology-Enhanced Role-Play for Intercultural Learning Contexts
}

\author{
Mei Yii Lim ${ }^{1}$, Michael Kriegel ${ }^{1}$, Ruth Aylett ${ }^{1}$, Sibylle Enz ${ }^{2}$, Natalie Vannini ${ }^{3}$, \\ Lynne Hall ${ }^{4}$, Paola Rizzo ${ }^{5}$, and Karin Leichtenstern 6 \\ 1 School of Mathematical and Computer Sciences, Heriot Watt University, \\ Edinburgh, EH14 4AS, Scotland \\ \{myl, michael, ruth $\}$ @macs. hw . ac.uk \\ 2 Otto-Friedrich-Universität Bamberg, \\ Kapuzinerstrasse 16, D-96045 Bamberg, Germany \\ sibylle.enz@uni-bamberg.de \\ 3 Universität Würzburg, Lehrstuhl für Psychologie IV \\ Röntgenring 10, D-97070 Würzburg, Germany \\ natalie.vannini@psychologie. uni-wuerzburg.de \\ 4 School of Computing and Technology, University of Sunderland \\ lynne.hallesunderland.ac.uk \\ 5 Interagens s.r.l., Via G. Peroni 444, 00131 Rome, Italy \\ p.rizzo@interagens.com \\ ${ }^{6}$ Universität Augsburg, Lehrstuhl für Multimedia-Konzepte und Anwendungen \\ Eichleitnerstr. 30, 86159 Augsburg, Germany \\ karin.leichtenstern@informatik.uni-augsburg.de
}

\begin{abstract}
Role-play can be a powerful educational tool, especially when dealing with social or ethical issues. However while other types of education activity have been routinely technology-enhanced for some time, the specific problems of supporting educational role-play with technology have only begun to be tackled recently. Within the eCIRCUS project we have designed a framework for technology-enhanced role-play with the aim of educating adolescents about intercultural empathy. This work was influenced by related fields such as intelligent virtual agents, interactive narrative and pervasive games. In this paper we will describe the different components of our role-play technology by means of a prototype implementation of this technology, the ORIENT showcase. Furthermore we will present some preliminary results of our first evaluation trials of ORIENT.
\end{abstract}

\section{Introduction}

Drama and play have been used for education for a very long time [1] and have resulted in game-based educational approaches. These provide a means of overcoming real-world social restrictions, placing the player in a role that may or may not be socially acceptable in real life, such as a medical doctor or a thief. Games allow the player to escape into fantasy worlds, encourage exploration of exciting things, people, and places that are otherwise inaccessible in the real 
world, inducing a 'suspension of disbelief' in the player. Learning often takes place while the game is played, with immediate feedback. The subject to be learned is directly related to the game environment where constant cycles of hypothesis formulation, testing and revision are evoked as the player experiences continuous cycles of cognitive disequilibrium and resolution.

This paper explores an approach to an educational role-play (RP) game developed in the ORIENT showcase of the eCIRCUS1 project, employing innovative technologies to foster social and emotional learning in the adolescent age group. With globalisation, dealing with cultural difference and diversity has become a widespread task and is both challenging and enriching. In looking for ways to help the process of acculturation of adolescents from emigrant backgrounds, there were a number of reasons for not focusing on them directly. Firstly, they form a heterogeneous group with a multitude of cultures and languages. It would be infeasible to try to capture all these in a computer-based system. More than this, acculturation is a two-way process in which both the incoming group and the host group have to negotiate a common understanding. It was therefore decided to focus on the host group, and to foster intercultural sensitivity through the development of intercultural empathy.

By increasing the social and intercultural competence of the host adolescents, ORIENT aims at diminishing discrimination and hence lowering the mental stress of peers from a migration background. ORIENT offers a virtual roleplay environment inhabited by autonomous artificial agents that interact with and react to a group of learners. Hence, learners may collaboratively improve their perception of and alter their emotional reactions and attitudes to members of other cultures in a secure social setting, while interacting with the virtual environment through a set of engaging and immersive interaction devices.

\section{Related Work}

Pervasive gaming takes virtual narrative elements out into the real world, focusing on introducing game elements into the everyday life of players. They exploit interaction devices such as handhelds to display virtual world elements [2] and employ technology support through which human game-masters can exercise higher amounts of control over the game experience [3]. The Enhanced Reality Live Role-Playing of the IPerG project, in the area of pervasive games, has successfully carried out a number of pervasive games in real spaces (e.g. 4). These focused on the idea of linking the real world into the story world [5], through for example, using unwitting inhabitants of the real world as props for pervasive game players. Some other groups have also produced educational pervasive games. Virus $[6]$ is a game in which learners take on the role of a virus and transmit it via specially-designed mobile devices called Thinking Tags by getting within proximity of other users. This demonstrated a complex diseasepropagation algorithm in a real world setting. In Paranoia syndrome [7, learners can take on the roles and skills of a technician, doctor or scientist. The Virtual

\footnotetext{
${ }^{1}$ http://www.e-circus.org/
} 
Savannah [2] took child learners out of the classroom setting and through the use of handheld devices made it possible for them to view their school playing field as a Savannah on which they role-played lions. A more recent and more problem-oriented role-play, the Environmental Detective [8] used a whole university campus as its story-world, while artistically oriented pervasive games such as Uncle Roy All Around You and I Can See You Now 2 have used whole cities as the game environment.

The use of large-scale real-world spaces for role-play suits some applications, but others require a dedicated space, and can be thought of as stage-based roleplay. This is true of many of the existing educational role-plays. A stage-based environment can be thought of as a sensor-rich pervasive computing environment including large display systems in which virtual actors and graphical worlds can play a more prominent role than is feasible when only hand-held devices are used. An early example of the stage-based approach is the Mission Rehearsal Exercise 9] in which a single human participant interacts with virtual characters in a stressful and dramatic situation (peacekeeping) using structured speech. This work has been extended into a more augmented reality environment using 'flats' - large display screens within a real world space, but has limited interaction modalities. ORIENT also takes this approach for a role-play that aims to educate students in inter-cultural empathy employing a set of innovative interaction devices.

\section{The Game: ORIENT}

\subsection{The Story}

ORIENT is being developed for the 13-14 age group of boys and girls in the UK and Germany and is designed to be played by a group of 3 teenage users. Each one of them takes the role of a member of a spaceship crew. Their mission takes them to a small planet called ORIENT, which is inhabited by an alien race - the nature loving Sprytes. Portraying a fictional instead of an existing culture makes our application more flexible and suitable for users from diverse backgrounds. Furthermore, it allows us to exaggerate cultural differences for dramatic and educational purposes.

The Sprytes are not aware of the danger that their planet is in: a meteorite is on destruction course and unless someone stops it, it would mean the end of life on ORIENT. It is the users' task to prevent a catastrophe. To do that the users first have to befriend the Sprytes and ultimately cooperate with them to save their planet. Through interaction with the Sprytes, ORIENT promotes culturalawareness in the users, who have to put themselves into the shoes of guests to a strange and unknown culture. At the same time ORIENT acts as a team building exercise where users play as a single entity rather than as individuals. All users have the same goal in the game although their roles and capabilities differ. 


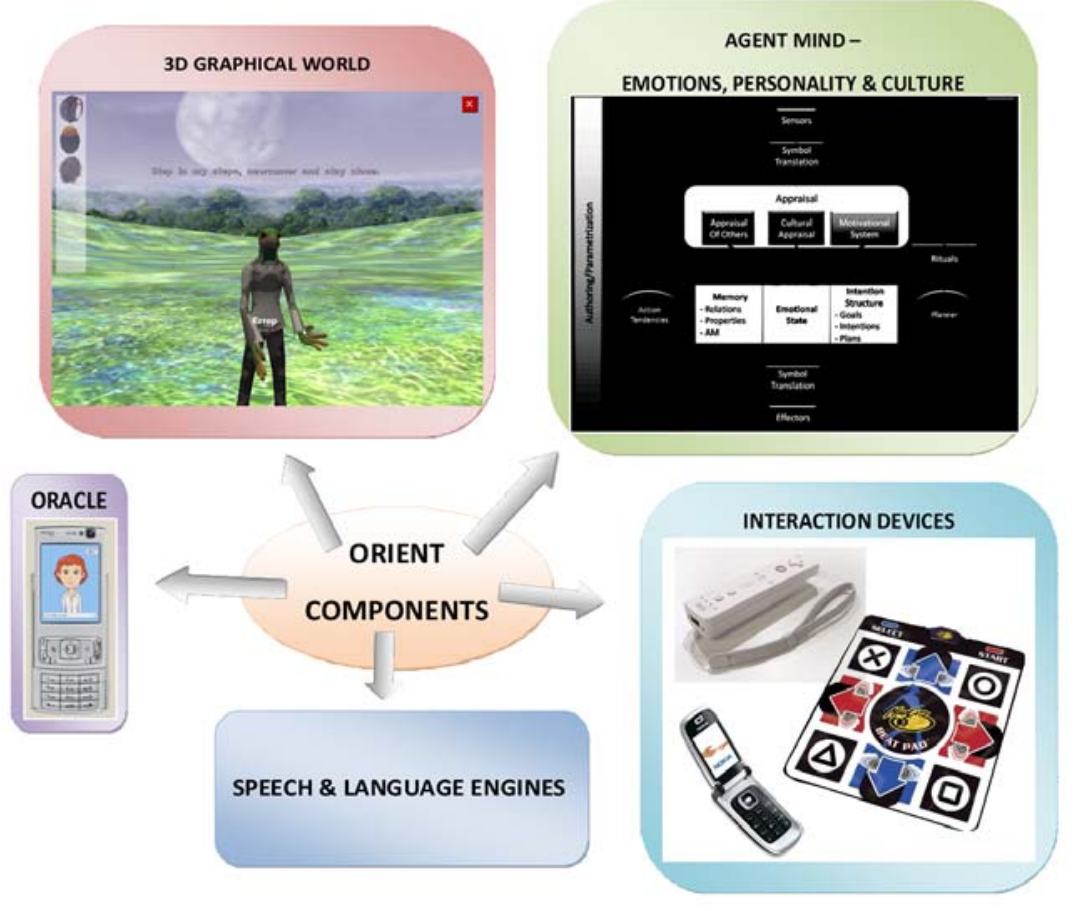

Fig. 1. ORIENT system components

\subsection{The ORIENT Prototype}

A prototype of ORIENT has been implemented consisting of the main components shown in Figure [1] Each component will be described separately in the next section. In this prototype a group of 3 users explores 4 different locations of the Sprytes' world. All users share a single first person perspective of the same 3D virtual world. Each user is equipped with a different interaction device (Section 4.3), all 3 of which are necessary to interact with the virtual Spryte characters. A Spryte character is implemented as an autonomous agent based on the FAtiMA [10] agent mind architecture (Section 4.1). Dialogues are treated by the agent mind as symbolic speech acts. When a Spryte speaks, a language engine transforms the speech act into natural language subtitles while a speech engine simultaneously generates the respective audio in an artifcial incomprehensible gibberish language. While the application is running, both the ORACLE (Section 4.2) and the Story Facilitator modules are constantly monitoring all events in the game world. The ORACLE uses this information to provide context-sensitive help and advice to the users. The Story Facilitator on the other hand, monitors the events in order to ensure an interesting story develops. This is achieved by directly influencing the game world, for example by introducing a new character in certain situations. 


\subsection{Culture in ORIENT}

According to Kluckhohn [1], culture is that part of behaviour which is learned by people as the result of belonging to some particular group. "It is the main factor which permits us to live together in a society, giving us ready made solutions to our problems, helping us to predict the behavior of others, and permitting others to know what to expect of us" (p. 25).

Classifications of cultures and a taxonomy on dimensions of cultural variability have been provided by authors including Hall 12 and Hofstede 13 . Hofstede defines the following dimensions of cultural variability: individualism-collectivism; uncertainty avoidance; power distance; and masculinity-femininity. These have been used to define the culture of the Sprytes. This is a tribal culture with a hierarchy (high power distance), depending highly on respect and age. This is reinforced by the fact that Sprytes are militarily active and believe in using force and power to influence others and to protect their habitat. They are a collectivistic culture (individualism-collectivism), which makes them compassionate

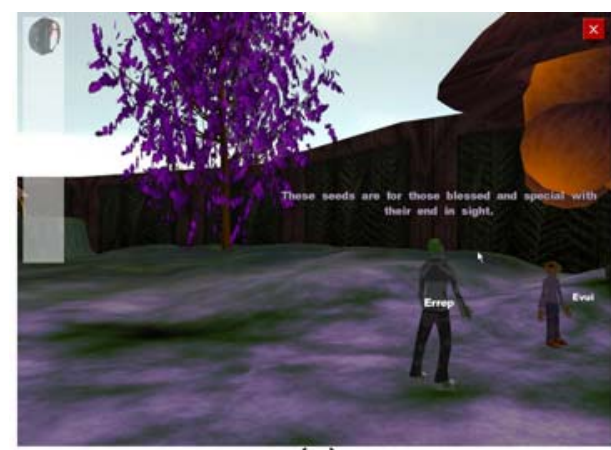

(a)

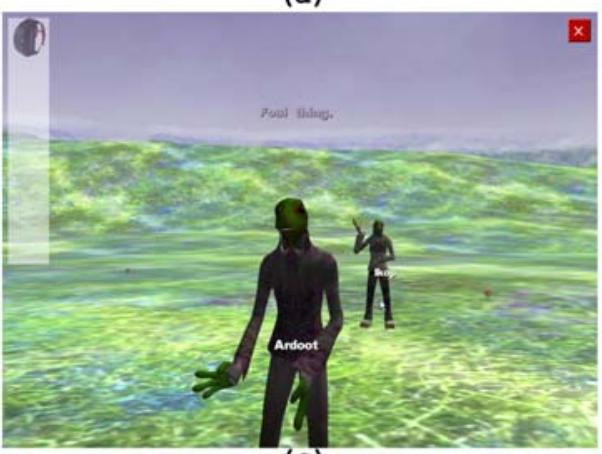

(c)

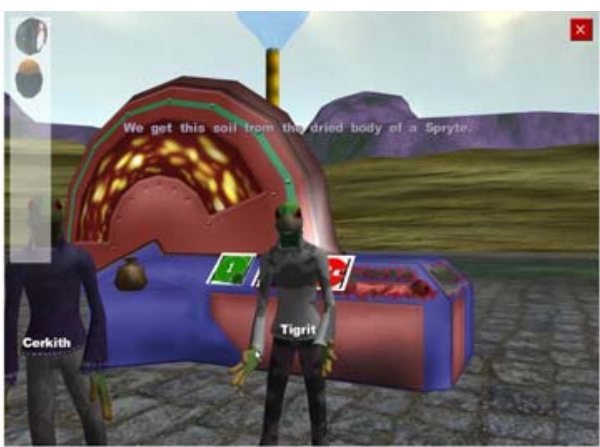

(b)

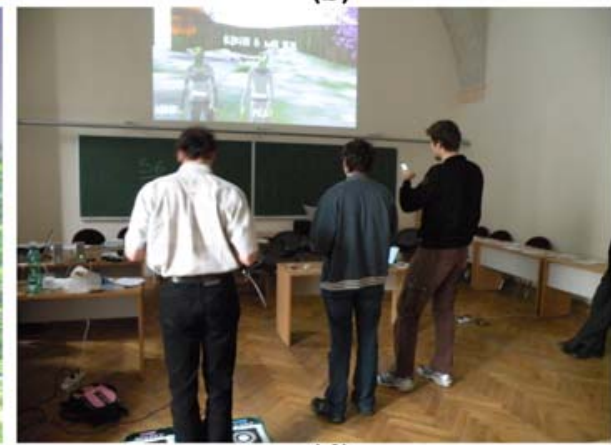

(d)

Fig. 2. (a) Educating a child Spryte for picking seedpod from the tree which is against the Spryte's culture; (b) A Spryte explaining their life cycle; (c) Angry gesture to the user for stepping on a little tree; (d) users interacting with ORIENT 
with each other, and live in groups where the majority holds power. They are highly traditional in their ways and view uncertainty as a threat (uncertainty avoidance) but exceptions do exist in younger Sprytes. Gender (masculinityfemininity) is absent from the Sprytes and the graphical representation of the Sprytes is intended to be ambiguous from this point of view as can be observed in Figure 2(a-c).

\section{System Components}

\subsection{Virtual Actors}

The use of virtual actors is one of the most important ways of shaping the narrative experience in RP games. In order to produce competent and responsive virtual actors, ORIENT draws upon previous work in AI in the fields of affectivecognitive models, intelligent synthetic characters and embodied conversational agents (ECAs), and interactive narrative. Affective models are seen here as a key component of virtual actors given the need to affectively engage participants and spectators in the dramatic environment. These were absent from early work in virtual actors, as in IMPROV [14] and the Virtual Theater project [15] in which virtual actors operated purely within graphics environments and were at most semi-autonomous.

The ORIENT software is being built upon FAtiMA [10, an agent architecture with an emotional continuous planner. We have extended FAtiMA with concepts from the PSI [16, 17. model, which bases all actions on the fulfilment of basic physiological needs. Here, we take the body-mind 18 view of emotion where emotions do not rely purely on reasons but there exists an interaction between physiological processes and the cognitive processes in a human action regulation system.

Employing FAtiMA, the agent's decision making processes are influenced by the OCC [19] cognitive appraisal. OCC is a widely used taxonomy for categorising and explaining emotional occurrences. The advantage of using the OCC model for ORIENT characters is that empathy can be modelled easily because it directly relates to the appraisal of events as they impact on others. It is - as far as we know - the only model that provides a formal description of non-parallel affective empathic outcomes. Additionally, the OCC model includes emotions that concern behavioural standards and social relationships based on like/dislike, praiseworthiness and desirability for others, allowing appraisal processes that take into consideration cultural and social aspects, important for the believability of ORIENT characters. Characters are entirely 'in-role' in that they select actions according to their immediate goals and environment, portraying affective engagement with their own situation and each other. This lays the basis for affective engagement of the learners with the characters.

The PSI model extends the empathic modelling to more emotional outcomes than those described by the OCC model. Emotions within the PSI model are conceptualised as specific modulations of cognitive and motivational processes. The motivational system serves as a quick adaptation mechanism of the agent 
to a specific situation and may lead to a change of belief about another agent [20, important for conflict resolution among ORIENT characters. Utilising PSI, processes in ORIENT characters become self-regulatory and parallel, driven by needs that emerge from activities in the environment or grow over time. Each character will continuously perceive the environment and create intentions that may satisfy its needs at a particular instance of time. One of these intentions is then selected for execution based on the degree it satisfies the character's needs and its probability of success. Through trial and error by executing different goals, ORIENT characters learn. The character's experiences are stored in an autobiographic memory 21] for future reference, thus, permitting adaptive and flexible behaviour in the dynamic RP environment so that the RP is open-ended rather than pre-scripted. For more information on the ORIENT architecture, please refer to $[22]$.

\subsection{The ORACLE}

The ORACLE (Onboard Resource Agent for Cultural and Liaison Engagements) is an embodied computer character that aims at enhancing user's learning in the game. The ORACLE as shown in Figure 1 runs on a Nokia N95 phone. It plays the role of a human facilitator in fostering users' motivation and keeping them engaged, stimulating group collaboration, keeping the users' focus on the task and providing help during the mission. Its advice focuses mainly on facilitating and stimulating the intercultural learning processes but also includes more pragmatic help with the technology.

The ORACLE stimulates users' reflection on events and outcomes of ORIENT by asking appropriate questions and commenting on users' actions. Help is provided as hints to the team when it notices that the team is not making any progress. Users can also ask questions by selecting buttons on the graphical user interface. The ORACLE mind mainly consists of a production system containing two types of rules: "reactive" ones, that fire when the user asks for help, and "proactive" ones, that fire according to the occurrence of specific events in ORIENT.

\subsection{Interaction Modalities}

Approaches such as tangible user interfaces, mobile user interfaces and augmented reality all attempt to combine the physical world of users and the virtual world of applications to make interactions easier, quicker, more fun and more engaging for both single and multi-user interactions. Including the real world in the interaction process offers new possibilities in performing computer supported tasks. Research identifies that increasing the integration of the user's physical environment will render interaction more intuitive and engaging (eg. 23, 24]). Innovative interaction devices that provide more intuitive interfaces to express affect has been shown to enhance empathic engagement 25]. Additionally, empirical evidence is found that a more positive impact on collaboration can be achieved in learners when using a computer with multiple input devices and cursors than when using one without these interaction facilities (eg. [26, 27, 28]). 
It was observed that by assigning each user a specific role tied to an interaction device with a dedicated function, more organised interaction within a group is produced, balancing the level of interactivity and avoiding dominant users 28 .

Taking these studies as guidelines, ORIENT's user interface was designed to be physical and tangible reducing the discrepancy between action and perception. Interaction is supported through large and micro screens, physical interfaces and multi-modal interaction devices. Full body interaction and movement in the physical space, particularly important in social behaviour and culturally specific interaction are supported (see Figure 2(d)). Each user is assigned a role which relates to a specific interaction device - a mobile phone, a Dance Mat or a WiiMote - that has unique functions, necessary to achieve the overall goal of the game.

The Nokia NFC 6131 mobile phone supports RFID-based input and speech recognition. The user who is assigned to use the phone selects objects by touching RFID tags-embedded objects that also have existence in the virtual world. To grab a virtual character's attention, he calls out a "magic word" (the character's name).

A second user uses a Dance Mat to navigate the virtual world. This interface has two advantages: first it bears a resemblance to real-world navigation in the sense that the user has to take actual steps and second since it only occupies the user's feet, it allows this user to operate the ORACLE at the same time.

The WiiMote is used for three-dimensional gesture recognition based on motion data derived from accelerometer sensors. We use the Wiigle library for this purpose 29]. The third user performs different gestures using the WiiMote as a communication channel with the Sprytes. The use of gestures for communication eliminates the need for natural language processing.

\section{$5 \quad$ Interaction Scenario}

During the mission, the users will witness the Sprytes eating habits - eating only seedpods that have dropped onto the ground (Figure 2(a)), life cycles - recycling the dead (Figure 2(b)), educational styles, family formation and value system trees are sacred (Figure 2(c)). An example scenario that is related to the Sprytes' eating habit is described below:

The interaction starts with the users greeting the Sprytes (performing the greeting gesture using the WiiMote). Then, the users witness a Spryte picking a seedpod from the ground and eating it. On the other hand, there will be a child Spryte who picks a seedpod from the tree. Once the child picked a seedpod from the tree, an adult Spryte will start the education process (because picking or eating seedpods from trees is forbidden in the Spryte culture) from which the users can learn about the Sprytes' culture. If the users approach a tree (stepping forward on the Dance Mat in the direction of a tree), they will be warned by one of the Sprytes about their inappropriate behaviour. If the warning is ignored and the users pick a seedpod from the tree (perform the pick gesture using the WiiMote and scan a RFID-embedded seedpod), the Sprytes will be angry with the 
users. A friendly Spryte might put in a good word for the users with his angry mate in this case. At this point, the Story Facilitator might interrupt by creating an external event, for example, a meteor hitting one of the Sprytes. The users can then act with the help of the ORACLE to cure the dying Spryte and by doing so, achieve redemption. If the users pick a seedpod from the ground, they will be invited for a meal together with the Sprytes. The users can choose to accept or reject the invitation (performing accept or reject gesture using the WiiMote) and their response affects future relationship with the Sprytes.

In the above scenario, the users have possibilities of making "right" or "wrong" choices thus highlighting the conflict management aspects of multi-cultural integration. Through direct feedback from the interaction, the users can analyse the appropriateness or suitability of their action. This coupled with post-role-play reflection or debriefing will help the users to transfer their experiences to real-world settings, hence, learn to adapt and accept differences among cultural groups.

\section{Evaluation and Discussion}

The ORIENT prototype has been evaluated in a lab-based, small-scale study in the UK and Germany with a total of 12 adolescents respectively. Each evaluation session took approximately 2 hours (including device training, actual ORIENT interaction and filling out the questionnaires). The key aim is to test the suitability of ORIENT as a tool for:- (a) fostering cooperation/collaboration; and (b) fostering reflection on intercultural problems. The evaluation framework is placed within the RP scenario itself, making the evaluation part of the interaction rather than a separate experience. The users operated as members of "Space Command" throughout the evaluation. To support this in-role approach, questionnaires and training videos were designed in a "Space Command" style and our evaluation team members were acting according to predefined roles. The two hypotheses were evaluated using post-interaction questionnaires (Cultural Intelligence Scale (CIS, [30]); Intergroup Anxiety Scale [31] General Evaluation Scale 32 ) and by interaction observation (Team cooperation, Solution-orientation, Empathy, Egocentrism, Small-Talk, Integration, Interaction, and Group mood).

The initial results indicate that the prototype and the use of the different interaction devices have rudimentarily the potential to foster cooperation among the user group. The groups reported quite positive feedback regarding their interaction. One group expressed that they had the feeling they had played very well together as a team. The participants were capable to point out similarities and differences between their own and the culture of the Sprytes and expressed rather positive feeling towards the Sprytes.

The technical evaluation focused on the experience of interacting with ORIENT (ORIENT Evaluation Questionnaire), the usability of the ORACLE (ORACLE Evaluation Form), and on the usability of the interaction devices (Device Questionnaire). The participants found it interesting to handle the different devices, and that all devices were needed to accomplish the interaction with the Sprytes despite the fact that it took them quite a while to be able to control the devices. 
Some issues were discovered during the evaluation including the Sprytes' personality, interaction devices and the story content. It was found that believability as well as the emotional impact of the drama on the users could be fostered by giving the individual Sprytes more distinctive personalities as they currently appear as cultural stereotypes. In order to enable the users to explore, understand, and flexibly react to the cultural encounter with and the specific problems of the Spryte culture, the interaction with the virtual world should be even more intuitive and seamless: sometimes the users found it hard to perform certain WiiMote gestures or pronounce characters' names correctly. Furthermore, the software needs to be enhanced content-wise in order to make the encounter with the Spryte culture a pedagogically meaningful experience, for example, adding content that may lead to some kind of conflict with the Sprytes, either a vicariously experienced conflict located within the Spryte culture, or a "real" conflict between the culture of the Sprytes and the user group.

\section{Conclusion}

The ORIENT software provides a role-play and story-framework for virtual social actors to interact with users in a number of different ways so as to create inter-cultural empathy. It employs tangible interaction modalities to increase users' motivation to learn about the Sprytes' culture and their engagement in the interaction, at the same time to enhance collaboration among themselves. It exhibits the potential of technology-enhanced role-play to support social and emotional learning in complex social situations without the risks that the learner faces in a real social situation due to the secure settings for experimentation with new behavioural strategies.

\section{Acknowledgements}

This work was partially supported by European Commission (EC) and was funded by the eCIRCUS project IST-4-027656-STP with university partners Heriot-Watt, Hertfordshire, Sunderland, Warwick, Bamberg, Augsburg, Würzburg plus INESCID and Interagens. The authors are solely responsible for the content of this publication. It does not represent the opinion of the EC, and the EC is not responsible for any use that might be made of data appearing therein.

\section{References}

[1] Crawford, C.: The Art of Computer Game Design, Chapter 2: Why Do People Play Games? Washington State University (1997), http://www.vancouver.wsu.edu/fac/peabody/game-book/Chapter2.html

[2] Benford, S., Crabtree, A., Flintham, M., Drozd, A., Anastasi, R., Paxton, M., Tandavanitj, N., Adams, M., Row-Farr, J.: Can you see me now? ACM Trans. Comput.-Hum. Interact. 13(1), 100-133 (2006) 
[3] Söderberg, J., Waern, A., Åkesson, K.P., Björk, S., Falk, J.: Enhanced reality live role playing. In: Workshop on Gaming Applications in Pervasive Computing Environments, Second International Conference on Pervasive Computing, Vienna, Austria (2004)

[4] Lindt, I., Ohlenburg, J., Pankoke-Babatz, U., Ghellal, S.: A report on the crossmedia game epidemic menace. In: Computers in Entertainment (2007)

[5] Stenros, J., Montola, M., Waern, A., Jonsson, S.: Play it for real: Sustained seamless life/game merger in momentum. In: Proceedings of DiGRA 2007 Situated Play conference, Tokyo, pp. 121-129 (2007)

[6] Collella, V., Bororvoy, R., Resnick, M.: Participatory simulations: Using computational objects to learn about dynamic systems. In: SIGCHI conference on Human factors in computing systems (CHI 1998), Los Angeles, USA (1998)

[7] Heumer, G., Carlson, D., Kaligiri, S.H., Maheshwari, S., Hasan, W.U., Jung, B., Schrader, A.: Paranoia syndrome - a pervasive multiplayer game using pdas, rfid, and tangible objects. In: Third International Workshop on Pervasive Gaming Applications on Pervasive Computing 2006, Dublin, Ireland (2006)

[8] Klopfer, E., Squire, K.: Environmental detectives: the development of an augmented reality platform for environmental simulations. In: Educational Technology Research and Development, pp. 203-228 (2008)

[9] Hill, R., Gratch, J., Marsella, S., Rickel, J., Swartout, W.: Virtual humans in the mission rehearsal exercise system. In: Künstliche Intelligenz (2003)

[10] Dias, J., Paiva, A.: Feeling and reasoning: A computational model for emotional characters. In: Bento, C., Cardoso, A., Dias, G. (eds.) EPIA 2005. LNCS (LNAI), vol. 3808, pp. 127-140. Springer, Heidelberg (2005)

[11] Kluckhohn, C.: Culture and Behavior. The Free Press of Glencoe, New York (1988)

[12] Hall, E.T.: Understanding Cultural Differences. Intercultural Press, Yarmouth (1988)

[13] Hofstede, G.: Cultures and Organisations. McGraw-Hill, London (1991)

[14] Perlin, K., Goldberg, A.: Improv: A system for scripting interactive actors in virtual worlds computer graphics. In: International Conference on Computer Graphics and Interactive Techniques, pp. 205-216. ACM, New York (2006)

[15] Rousseau, D., Hayes-Roth, B.: A social-psychological model for synthetic actors. In: Proceedings of the 2nd International Conference on Autonomous Agents (1998)

[16] Dörner, D.: Bauplan für eine Seele. Rowohlt Taschenbuch, Reinbek (2001)

[17] Dörner, D.: The mathematics of emotions. In: Frank Detje, D.D., Schaub, H. (eds.) Proceedings of the Fifth International Conference on Cognitive Modeling, Bamberg, Germany, April 10-12, pp. 75-79 (2003)

[18] Damasio, A.: Descartes' Error: Emotion, Reason and the Human Brain. Gosset/Putnam Press, New York (1994)

[19] Ortony, A., Clore, G., Collins, A.: The cognitive structure of emotions. Cambridge University Press, Cambridge (1988)

[20] Lim, M.Y.: Emotions, Behaviour and Belief Regulation in An Intelligent Guide with Attitude. PhD thesis, School of Mathematical and Computer Sciences, Heriot-Watt University, Ediburgh, Edinburgh (2007)

[21] Ho, W.C., Dautenhahn, K., Nehaniv, C.L.: Computational memory architectures for autobiographic agents interacting in a complex virtual environment: A working model. Connection Science 20(1), 21-65 (2008)

[22] Lim, M.Y., Dias, J., Aylett, R., Paiva, A.: Improving adaptiveness in autonomous characters. In: Prendinger, H., Lester, J.C., Ishizuka, M. (eds.) IVA 2008. LNCS (LNAI), vol. 5208, pp. 348-355. Springer, Heidelberg (2008) 
[23] Fails, J., Druin, A., Guha, M., Chipman, G., Simms, S., Churaman, W.: Child's play: A comparison of desktop and physical interactive environments. In: Conference on Interaction Design and Children, pp. 48-55 (2005)

[24] Dow, S., Mehta, M., Harmon, E., MacIntyre, B., Mateas, M.: Presence and engagement in an interactive drama. In: Proceedings of the SIGCHI conference on Human factors in computing systems, pp. 1487-1484 (2007)

[25] Paiva, A., Prada, R., Chaves, R., Vala, M., Bullock, A., Andersson, G., Höök, K.: Towards tangibility in gameplay: building a tangible affective interface for a computer game. In: ICMI 2003: Proceedings of the 5th international conference on Multimodal interfaces, pp. 60-67. ACM, New York (2003)

[26] Inkpen, K., Ho-Ching, W., Inkpen, K.H.C., Scott, S., Shoemaker, G.: This is fun! we're all best friends and we're all playing: supporting children's synchronous collaboration. In: Proceedings of the 1999 conference on Computer support for collaborative learning (1999)

[27] Mandryk, R., Inkpen, K., Bilezikjian, M., Klemmer, S., Landay, J.: Supporting children's collaboration across handheld computers. In: Proceedings of the SIGCHI conference on Human factors in computing systems, New York, USA (2001)

[28] Leichtenstern, K., André, E., Vogt, T.: Role assignment via physical mobile interaction techniques in mobile multi-user applications for children. In: European Conference on Ambient Intelligence, Darmstadt, Germany (2007)

[29] Rehm, M., Bee, N., André, E.: Wave like an egyptian accelerometer based gesture recognition for culture specific interactions. In: HCI 2008 Culture, Creativity, Interaction (2008)

[30] Ang, S., Van Dyne, L., Koh, C., Ng, K.Y., Templer, K.J., Tay, C., Chandrasekar, N.A.: Cultural intelligence: Its measurement and effects on cultural judgment and decision making, cultural adaptation and task performance. Management and Organisation Review 3, 335-371 (2007)

[31] Stephan, W.G., Diaz-Loving, R., Duran, A.: Integrated threat theory and intercultural attitudes: Mexico and the united states. Journal of Cross-Cultural Psychology 31, 240-249 (2000)

[32] Wright, S.C., Aron, A., McLaughlin-Volpe, T., Ropp, S.A.: The extended contact effect: Knowledge of cross-group friendships and prejudice. Journal of Personality and Social Psychology 73, 73-90 (1997) 